\title{
Predictive Value of ERCC1 mRNA Level and Pretreatment EBV-DNA Virus Load in Stage II Nasopharyngeal Carcinoma Patients Receiving Intensity-Modulated Radiotherapy with Concurrent Cisplatin
}

\section{Li Hua}

the Forth Affiliated Hospital of Guangxi Medical University

\section{Shaojun Chen}

the Forth Affiliated Hospital of Guangxi Meddical University

\section{Mengzhuan Wei}

the Forth Affiliated Hospital of Guangxi Medical University

\section{Yongqi Shen}

\section{Liuzhou Municipal Liutie Central Hospital}

Jianxin Long

qinzhou hospital of traditional chinese medicine

Zhan Lin

The Yulin First People's Hospital

\section{Yiliang Meng}

The Baishe People's Hospital

\section{Ping Yin}

The Third Xiangya Hospital of Central South University

haixin huang ( $\nabla$ huanghaixinliuzhou@126.com)

the Forth Affiliated Hospital of Guangxi Medical University https://orcid.org/0000-0002-4932-7667

\section{Xiaoning Tu}

the Forth Affiliated Hospital of Guangxi Medical University

\section{Min Yao}

University Hospitals Cleveland Medical Center,Case Western Reserve University

Research article

Keywords: ERCC1 mRNA, EBV-DNA, nasopharyngeal carcinoma, intensity-modulated radiation, concurrent chemoradiation, overall survival, progression-free survival 
Posted Date: July 16th, 2020

DOl: https://doi.org/10.21203/rs.3.rs-41538/v1

License: (c) (i) This work is licensed under a Creative Commons Attribution 4.0 International License. Read Full License 


\section{Abstract}

Background: The protein expression of ERCC1 in DNA repair genes was related to resistance platinum and predicting treatment outcomes in various malignant carcinoma ,the level of plasma Epstein-Barr

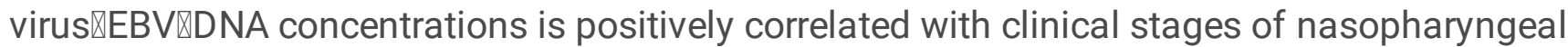
carcinoma(NPC), but the predictive value of ERCC1 mRNA and EBV-DNA level for stratified treatment with stage II NPC is unclear precisely. This study aimed to assess the predictive value of combined EBV-DNA and ERCC1 in stage II NPC patients treated with intensity-modulated radiotherapy (IMRT) with concurrent cisplatin and provide guidance for future stratified treatment.

Methods: A total 78 stage II NPC patients who received IMRT and concurrent cisplatin-based chemotherapy had measurements of ERCC1 mRNA and pre-treatment EBV DNA levels by real-time PCR (RT-PCR) analysis were analyzed. Associations of ERCC1 mRNA and pre-treatment EBV DNA levels with clinical characteristics and survivals were evaluated.

Results: Cut-off value of ERCC1 mRNA obtained from ROC curve was used and there were significant differences in progression-free survival (PFS) and overall survival (OS) between high expression group as compared to low expression group ( $P=0.021$ and 0.030 , respectively). Patients with pretreatment $\mathrm{EBV}$ DNA $<2000$ copies/ml had significantly better PFS $(P=0.024)$ than those with pretreatment EBV-

DNA $\geq 2000$ copies $/ \mathrm{ml}$, but there was no significant difference in OS $(P=0.062)$. Patients were divided into three groups by combination of ERCC1 mRNA and EBV-DNA level ERCC1 mRNA low expression/pre EBVDNA<2000 copies/ml, ERCC1 mRNA low expression/pre EBV-DNA $\geq 2000$ copies/ml, ERCC1 mRNA high expression/pre EBV-DNA $\geq 2000$ copies/ml. In these groups, 1-year, 3-year, 5-year OS were 100\%, 100\%, $100 \% ; 100 \%, 94.1 \%, 90.9 \% ; 100 \%, 85 \%, 72.9 \%$, respectively $(P=0.038) ; 1$-year, 3-year, 5-year PFS were $100 \%, 100 \%, 100 \% ; 97.1 \%, 91.2 \%, 84.8 \% ; 95 \%, 85 \%, 71.4 \%$, respectively $(P=0.028)$. Multivariate analysis showed combination of ERCC1 mRNA and EBV-DNA levels remained independent prognostic factor but not ERCC1 mRNA and EBV-DNA alone.

Conclusion: Combined ERCC1 mRNA and pre EBV-DNA is a better prognostic factor in stage II NPC patients treated with concurrent chemoradiation. Patients with ERCC1 mRNA high expression/pre EBV$\mathrm{DNA} \geq 2000$ copies/ml should be treated with more aggressive regimen.

\section{Background}

Nasopharyngeal carcinoma (NPC) is one of the most common malignancies in Southern China with an incidence rate of 20-30/10000 [1, 2]. Non-keratinizing carcinoma (WHO 2005 classification), especially the undifferentiated type of Non-keratinizing carcinoma, is the major pathological type in regions with high incidence [3], which is more sensitive to chemoradiotherapy. Cisplatin is the standard concurrent chemotherapeutic agent in advanced NPC(stage III-IV)[4], due to its inhibitory effect on the tumor cells recovery from sub-lethal and potentially lethal radiation damage [5]. 
NCCN guidelines recommend concurrent chemoradiation for stage II NPC, however the role of chemotherapy in stage II NPC is still controversial. A phase III randomized controlled trial revealed improved 5-year overall survival (OS) rates in stage II NPC who received concurrent chemoradiotherapy compared to radiotherapy alone ( $94.5 \%$ vs $85.8 \% ; P=0.007$ ) [6]. In contrast, data from the Real-World Study (RWD) showed that patients with stage II NPC did not benefit much with additional chemotherapy; those treated with radiotherapy alone had excellent long-term survival [7]. It is possible selection of

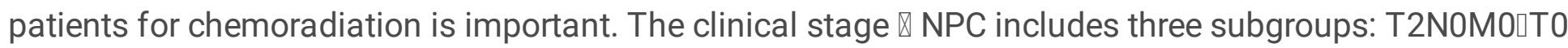
$\sim$ 1N1M0, and T2N1M0. Long-term follow-up data showed that the survivals of these subgroups were different [8]. However, the current staging system based solely on anatomical information cannot fully reflect the risk factors stratification of stage II NPC; there is biological heterogeneity among tumor individuals. Therefore, there are some limitations in guiding stage II NPC treatment through clinical staging system.

Repair of DNA damages is a key process after cancer cells exposed to radiotherapy and chemotherapy [9]. Mediators that are associated with DNA damage repair process may affect the outcomes of radiotherapy and chemotherapy [9]. Excision repair cross-complementation group 1 (ERCC1) act as a rate-limiting enzyme in the nucleotide excision repair (NER) pathway [10-11]. Recently, increasing experimental and clinical evidences demonstrated that high ERCC1 expression was associated with resistance to platinum-based chemotherapy in gastric cancer, ovarian cancer, and lung cancer, and low ERCC1 expression predicted good survival of these patients [12-17]. In locoregionally advanced NPC treated with chemoradiotherapy, there were several studies used immunohistochemical techniques (IHC) to determine the expression of ERCC1 and found that high tumor ERCC1 expression predicted poor treatment response and survival [18-21]. However, the relationship between ERCC1 mRNA and treatment outcomes in NPC has not been established.

Epstein-Barr virus(EBV)DNA concentrations correlate positively with disease stage as well as exhibit prognostic importance in NPC [22]. Many published studies have shown that EBV DNA is an important biomarker for monitoring survival for all stages of disease [23-25]. In stage II NPC, our previous study found that the plasma EBV-DNA level one week after radiotherapy completion could predict 3-year and 5year recurrence and metastasis rate [26], but the predictive value of pre-treatment plasma EBV-DNA level have not been studied.

Understanding the underlying intrinsic factors would help us to predict the prognosis and select optimal treatments. However, whether combined ERCC1 and EBV-DNA is associated with prognosis in the prediction of concurrent chemoradiotherapy (CCRT) treatment outcomes and provide clinical guidance remains unclear. The subject of this study was to retrospectively assess the prognostic value of combined ERCC1mRNA with the level of pre-treatment the plasma EBV-DNA and survival for stage II NPC.

\section{Methods}

\section{Human NPC tissue samples}


All procedures performed in this study involving human participants were approved by Ethics Committee of the participating hospitals, and were in accordance with the 1964 Declaration of Helsinki. Informed consent was obtained from each patient. Human NPC tissues were collected from 78 patients who underwent CCRT between June 2012 and June 2015. All cases were biopsy-proven NPC and stage II disease according to the seventh edition TNM staging system. The median age was 46 years old (1873 years old) and the gender ratio (male vs. female) was 3.1:1. The clinicopathological characteristics of the NPC patients were presented in Table 1.

Table 1

Characteristics of the patients with stage II NPC patients

\begin{tabular}{|ll|}
\hline Patient characteristic & Number (\%) \\
\hline Median follow-up (months, rang) & $62 \mathrm{~m}(22 \mathrm{~m}-84 \mathrm{~m})$ \\
\hline Sex & 59 \\
\hline Male & 19 \\
\hline Female & \\
\hline Age (year) & 64 \\
\hline 区60 & 14 \\
\hline$\geq 60$ & \\
\hline T stage & 15 \\
\hline T1 & 63 \\
\hline T2 & \\
\hline N stage & 23 \\
\hline N0 & 55 \\
\hline N1 & \\
\hline TN stage & 23 \\
\hline T2N0 & 16 \\
\hline T1N1 & 39 \\
\hline T2N1 & \\
\hline Median ERCC1mRNA (Rang) & $119(0.456-1.411)$ \\
\hline Median EBV-DNA load (Rang) & $4089-2.02 \times 105)$ \\
\hline
\end{tabular}

\section{Chemoradiation treatment}


All patients were treated with intensity-modulated radiotherapy (IMRT) given once daily 5 times per week. The radiation dose was as follow: PGTV ${ }_{n x} 70.06 \mathrm{~Gy} / 31$ times, PGTV $\mathrm{nd} 70.06 \mathrm{~Gy} / 31$ times, $\mathrm{PTV}_{1}$ $66.03 \mathrm{~Gy} / 31$ times and PTV $254.25 \mathrm{~Gy} / 31$ times. All volumes were treated simultaneously.

Cisplatin $(80 \mathrm{mg} / \mathrm{m} 2)$ was given via intravenous infusion every 21 day for three cycles, beginning on the first day of radiotherapy.

\section{Response evaluation and follow-up studies}

At 12 weeks after completion of CCRT, magnetic resonance imaging (MRI) of nasopharynx and neck was obtained in all patients and the tumor response was evaluated according to the Response Evaluation Criteria in Solid Tumors(Version 1.1). Based on the tumor response, patients were divided into complete response group (CR), partial response group (PR), stable disease group (SD), or progressive disease (PD) group. The response rate (RR) was calculated as number of CR plus PR cases divided by all cases. All patients were followed every 3 months in the first year and every 6 months for the following years.

\section{Real-time PCR analysis}

RNA was extracted from the cancerous tissues using TRIzol reagent (Takara, Dalian, China) according to manufacturer's instructions, and cDNA was synthesized using PrimeScript 1st strand cDNA Synthesis Kit (Takara). ERCC1 expression level was detected by using SYBR Green real-time PCR in ABI7900 system (Applied Biosystems, Foster City, USA). GAPDH was used as an internal reference for ERCC1 mRNA expression. The primers for ERCC1: F, 5'-CCGCCAGCAAGGAAGAAA-3', R, 5'-CTGCCGAGGGCTCACAAT-3'; the primers for GAPDH: F, 5'-GAGATCCCTCCAAAATCAAGT-3', R, 5'-CTTCCACGATACCAAAGTTGT-3'. The mRNA expression of ERCC1 was calculated by using compared $\mathrm{Ct}$ method.

\section{Quantitative detection of EBV-DNA in plasma}

$3 \mathrm{ml}$ of blood was collected each time, added into the EDTA anticoagulant tube, centrifuged at $2000 \mathrm{R} /$ min for 5 min, and $200 \mu$ I of plasma was frozen at $-20{ }^{\circ} \mathrm{C}$ for standby. Extraction and amplification steps of EBV-DNA: put frozen plasma at room temperature, extract DNA in strict accordance with the instructions of EBV fluorescence quantitative polymerase chain reaction (RT-PCR) detection kit; detect gene amplification with mixed PCR reaction solution on $\mathrm{ABI} 7300$ PCR instrument, PCR reaction conditions: $93^{\circ} \mathrm{C}$ pre denaturation for $2 \mathrm{~min}, 93^{\circ} \mathrm{C} 45 \mathrm{~s}, 55^{\circ} \mathrm{C} 60 \mathrm{~s} .10$ cycles; $93{ }^{\circ} \mathrm{C} 30 \mathrm{~s}, 55^{\circ} \mathrm{C} 45 \mathrm{~s}, 30$ cycles. The calculation formula of plasma EBV-DNA concentration: $\mathrm{C}=\mathrm{q} \times(\mathrm{vdn} / \mathrm{VPC}) \times(1 / \mathrm{vext})$.

\section{Statistical analysis}

All the data analysis was performed with SPSS software (Version 23.0, SPSS Inc., Chicago, USA). The survival curves, the receiver-operator characteristic(ROC)curve and Forest map were drawing in GraphPad Prism 8.3 (GraphPad Software Inc., San Diego, CA, USA). The overall survival was defined as the time from start of treatment to death from any cause. The progression free survival was defined as the time from start of treatment to the observation of disease progress. Association between ERCC1mRNA expression, the level of EBV-DNA and clinicopathological characteristics were assessed by Chi-square 
test. The survival difference in OS and PFS between different groups was assessed by Kaplan-Meier plots. All statistical tests were two-sided, and $P$ values less than 0.05 were considered as statistically significant.

\section{Results}

\section{ERCC1 mRNA expression in NPC tissues and treatment response}

The mRNA expression levels of ERCC1 in NPC tissues determined by RT-PCR ranged from 0.456 to 1.412 with the median value of 1.119 .

To determine the diagnostic value of the ERCC1 mRNA to response, the data from 78 cases were analyzed by ROC curve analysis. The results showed that the area under the curve (AUC) was significantly larger than the area expected by chance alone $(P<0.0001,95 \% \mathrm{Cl}=0.917-0.960 ;$ Fig. 1$)$. The optimal cut-off value was 1.295 ; with sensitivity of $87.5 \%$ and a specificity of $81.4 \%$.

Using this cut-off value, ERCC1 mRNA expression was found significantly associated with $\mathrm{N}$ stage and TN stage but not significantly associated with gender, age or T stage (Table 2). Furthermore, using this cut-off value as dichotomy, 40/41 had complete response or partial response in the low expression group $(<1.295)$ and $30 / 37$ had complete response or partial response in the high expression group $(\geq 1.295)$. Those with low expression had significant higher treatment response rate than those with high expression ( $97.65 \%$ vs $81.08 \% ; P=0.043)$. 
Table 2

The relationship between ERCC1mRNA expression and clinical characteristics in stage II NPC patients

\begin{tabular}{|c|c|c|c|c|}
\hline Variables & Case & ERCC1mRNA & ERCC1mRNA & $P$ value \\
\hline & $\mathrm{n}(\%)$ & low expression & high expression & \\
\hline Sex & & & & 0.199 \\
\hline Male & 59 & 46 & 13 & \\
\hline Female & 19 & 12 & 7 & \\
\hline Age (year) & & & & 0.341 \\
\hline$\nabla 60$ & 64 & 49 & 15 & \\
\hline$\geq 60$ & 14 & 9 & 5 & \\
\hline T stage & & & & 0.329 \\
\hline T1 & 15 & 13 & 2 & \\
\hline T2 & 63 & 45 & 18 & \\
\hline $\mathrm{N}$ stage & & & & 0.012 \\
\hline NO & 23 & 23 & 0 & \\
\hline $\mathrm{N} 1$ & 46 & 35 & 11 & \\
\hline TN stage & & & & 0.000 \\
\hline T2NO & 23 & 23 & 0 & \\
\hline T1N1 & 16 & 14 & 2 & \\
\hline T2N1 & 39 & 21 & 18 & \\
\hline
\end{tabular}

\section{General treatment outcomes}

With median follow up of 62 months (range 22-84), the 1-year, 3-year and 5-year OS rates were 98.72\%, 93.59\% and $91.03 \%$, respectively, and the 1-year, 3-year and 5-year progression-free survival (PFS) rates were $97.4 \%, 92.3 \%$ and $86.5 \%$, respectively.

\section{The relationship between ERCC1 mRNA expression levels and treatment outcomes}

The Kaplan-Meier survival curves for OS and PFS comparing high ERCC1 mRNA expression and low ERCC1 mRNA expression using the cut-off value were shown in Fig. 2A and 2B. There were statistically significant difference in both OS and PFS. The 1-year, 3-year and 5-year OS were $100 \%, 85.0 \%, 72.9 \%$ in the high expression group versus $100 \%, 96.6 \%, 94.7 \%$ in the low expression group $(P=0.021)$. The 1 -year, 
3-year and 5-year PFS rates were $95 \%, 85 \%, 71.4 \%$ in the high expression group versus $98.3 \%, 94.8 \%$, $91.1 \%$ in the low expression group $(P=0.030)$.

\section{The EBV-DNA viral load and treatment outcomes}

Using pretreatment EBV-DNA load 2000 copies/ml as a cut-off [22], EBV-DNA viral load was found to be significantly associated with $\mathrm{T}$ stage and TN stage but not significantly correlated with gender, age or $\mathrm{N}$ stage (Table 3).

Table 3

The relationship between pre EBV-DNA level and clinical characteristics in stage II NPC patients

\begin{tabular}{|c|c|c|c|c|}
\hline Variables & Case & EBV-DNA & EBV-DNA & $P$ value \\
\hline & $\mathrm{n}(\%)$ & 『2000 copies/ml & $\geq 2000$ copies $/ \mathrm{ml}$ & \\
\hline Sex & & & & 0.395 \\
\hline Male & 59 & 20 & 39 & \\
\hline Female & 19 & 4 & 15 & \\
\hline Age (year) & & & & 1.000 \\
\hline$₫ 60$ & 64 & 20 & 44 & \\
\hline$\geq 60$ & 14 & 4 & 10 & \\
\hline T stage & & & & 0.035 \\
\hline T1 & 15 & 8 & 7 & \\
\hline T2 & 63 & 16 & 47 & \\
\hline $\mathrm{N}$ stage & & & & 0.619 \\
\hline NO & 23 & 8 & 15 & \\
\hline N1 & 55 & 16 & 39 & \\
\hline TN stage & & & & 0.018 \\
\hline T2NO & 23 & 8 & 15 & \\
\hline T1N1 & 16 & 9 & 7 & \\
\hline T2N1 & 39 & 7 & 32 & \\
\hline
\end{tabular}

The Kaplan-Meier survival curves for OS and PFS comparing high EBV-DNA load ( $\geq 2000 \mathrm{copies} / \mathrm{ml}$ ) and low EBV-DNA load (2000 copies/ml) were shown in Fig. 3A and 3B. There was a trend although not statistically significant difference in OS. The 1-year, 3-year and 5-year OS were $100 \%, 90.7 \%, 85.7 \%$ in the high EBV-DNA load group versus $100 \%, 100 \%$, and $100 \%$ in the low EBV-DNA load group $(P=0.062)$. But 
there was statistically significant difference in PFS. The 1-year, 3-year and 5-year PFS rates were 96.3\%, $88.9 \%, 80.1 \%$, in the high EBV-DNA load group versus $100 \%, 100 \%$ and $100 \%$ in the low EBV-DNA load group $(P=0.024)$.

\section{Combination of ERCC1 mRNA expression and EBV DNA viral load improved prognostic stratification}

Patients were stratified into three groups: low ERCC1 mRNA expression and low EBV-DNA load, low ERCC1 mRNA expression and high EBV-DNA load, high ERCC1 mRNA expression and high EBV-DNA load. There was no patient with high ERCC1 mRNA expression and low EBV-DNA. For these three groups, the 1year, 3-year, 5-year OS rates were 100\%, 100\%, 100\%; 100\%, 94.1\%, 90.9\%; 100\%, 85\%, 72.9\%, respectively ( $p=0.038)$; the 1-year, 3-year, 5-year PFS rates were100\%, 100\%, 100\%; 97.1\%, 91.2\%, 84.8\%; 95\%, 85\%, $71.4 \%$ respectively $(P=0.028)$. Figure $4 \mathrm{~A}$ and $4 \mathrm{~B}$ showed $\mathrm{OS}$ and PFS for these three groups.

\section{Univariate and multivariate analysis}

In univariate analysis, ERCC1 mRNA based on cut-off value and ERCC1 mRNA expression/pre EBV-DNA viral load were significant prognostic factors for OS $(P=0.037, P=0.023)$ and PFS $(P=0.043, P=0.014)$ (Fig. 5). However, after adjusting for covariates, multivariable analysis indicated only ERCC1 mRNA expression/pre EBV-DNA viral load was independent and significant negative prognostic factors for OS and PFS in patients stage II NPC. (HR: 4.290, 95\%Cl 1.220-15.082, $P=0.023$; HR: 3.461, 95\%Cl 1.2929.270, $P=0.014)$.

\section{Discussion}

In the present study, the ERCC1 mRNA expression level in NPC tissues determined by RT-PCR was examined rather than the ERCC1 protein level determined by the immunohistochemistry (IHC); the latter is more commonly used in most studies. Each method has its advantages and disadvantages. IHC procedure is easier to perform but with poorer reproducibility. In comparison, RT-PCR is more sensitive. In addition, ERCC1 has four protein subtypes 201, 202, 203 and 204. Only subtype 202 is related to the efficacy of platinum chemotherapy. However, the commonly used protein antibody detection method of ERCC1 cannot distinguish different subtypes $[27,28]$. A meta-analysis by Song et al suggested that RTPCR method is superior to IHC in term of detecting ERCC1 expression level to predict the outcomes of platinum-based chemotherapy in gastric carcinoma [29]. However, this is still controversial due to the differences in experimental reagents and criteria for assessment.

Our study showed that ERCC1 expression level was strongly correlated with N stage and TN stage but not significantly associated with gender, age or T stage. This is different from the results by Olaussen et al that found ERCC1 expression significantly correlated with age, gender and histological type, but not associated with tumor size and TNM stage [30]. Our study also showed that ERCC1 mRNA level was significantly associated with treatment outcomes in stage II NPC. Using the cut-off value obtained from 
ROC curve, ERCC1 mRNA can be divided into high expression and low expression groups. The OS and PFS of high expression group were significantly worse than that of low expression group. It is possible that the cancer cells with high ERCC1 expression have better ability to repair DNA damages, which is associated with resistance to platinum radio-chemotherapy leading to poor response to initial radiotherapy and chemotherapy.

Several studies have shown that EBV-DNA levels in advanced stage NPC are significantly higher than those in stage I and II NPC [31-33]. Du et al observed that the level of EBV-DNA was correlated with age, T stage, N stage and total stage in stage II-IV NPC [34]. However, TWU et al reported that EBV-DNA was not correlated with clinical and pathological factors in stage III NPC [35]. In the present study with stage II diseases, we found that EBV-DNA was significantly associated with T stage and TN stage but not significantly correlated with gender, age or $\mathrm{N}$ stage.

Furthermore, in advanced stage NPC, patients with a high level of EBV-DNA have worse survival outcomes, and several prognostic subgroups can be classified based on their plasma EBV-DNA levels. However, in stage I and II disease, there was no study on the prognostic value of pre-therapy plasma EBVDNA due to infrequent treatment failures. The optimal cut-off value of EBV-DNA has not been determined due to lack of harmonization of QPCR assay and different values were reported in different studies. Chai et al used 8000 copies/ml of pre-treatment plasma EBV DNA as a potential biomarker associated with OS for all stage NPC [36]. Lin et al, however reported that OS and relapse-free survival were significantly lower in patients with pretreatment plasma EBV DNA concentration $\geq 1500 \mathrm{copies} / \mathrm{ml}$ than those with < 1500 copies/ml [37]. Zhang et al in a meta-analysis of 14 prospective and retrospective control studies evaluated the relationship between EBV-DNA and half-life of EBV-DNA and survival and proposed a 4level risk stratification model. Patients with stage II disease and pre-treatment plasma EBV-DNA $<4000$ copies/ml could be down-staged to stage I and treated with radiation alone. However, patients with $\geq$ $4000 \mathrm{copies} / \mathrm{ml}$ pre-treatment plasma EBV-DNA should be re-classified into stage III and treated more aggressively [24]. Guo and colleague analyzed 979 newly diagnosed nonmetastatic NPC patients with RPA model and proposed a new staging model based on pre-treatment EBV DNA level using 2000 copies/ml as cut off value and anatomical information [22]. Based on Guo's study, we also used 2000 copies/ml EBV-DNA as a cut-off value in our study and found that stage II NPC also has high EBV-DNA concentrations with $70 \%$ of the patients having more than 2000 copies / $\mathrm{ml}$. Using this cut-off value, we show here that higher level of pre-treatment EBV DNA was associated with an increased risk of disease recurrence. There was a trend that higher level of pre-treatment EBV-DNA was associated with poor OS but did not reach statistical significance. Leung et al [38] also did not find a significant association between pre-treatment EBV DNA levels and the probability of distant failure $(P=0.0967)$ and the probability locoregional failure $(P=0.719)$ in stage I-II NPC. The failure to detect significant association of pre-treatment EBV-DNA and OS in our study is possible due to small sample size and short follow up.

Pretreatment EBV-DNA has been shown to be an independent prognostic factor for NPC in many studies. But ERCC1 mRNA level was not an independent prognostic factor in lung cancer, gastric cancer and pancreatic cancer [39]. In our study with stage II NPC, neither pretreatment EBV-DNA nor ERCC1mRNA 
was independent prognostic factors. However, combination of pretreatment EBV-DNA and ERCC1 mRNA was shown to be a significant independent prognostic factor for OS and PFS. By combining ERCC1 mRNA and pretreatment plasma EBV-DNA, stage II NPC can be divided into three subgroups: ERCC1 mRNA low expression/pre EBV-DNA < 2000copies/ml, ERCC1 mRNA low expression/pre EBV-DNA $\geq$ 2000 copies/ml, ERCC 1 mRNA high expression/pre EBV-DNA $\geq 2000$ copies $/ \mathrm{ml}$, and there were significant differences in OS and PFS between the three groups. Patients with ERCC1 mRNA high expression/pre EBV-DNA $\geq 2000$ copies/ml did significantly worse and possibly need more aggressive treatment and closer follow-up after treatment. On the other hand, patients with ERCC1 mRNA low expression/pre EBVDNA $<2000$ copies/ml did much better and their treatment could possibly be de-escalated and radiation alone without chemotherapy may be sufficient. The combination of ERCC1 mRNA and pre-treatment EBVDNA can improve prognostic value compared to using pre-treatment EBV-DNA alone in stage II NPC patients who have relatively better survival outcomes.

\section{Conclusions}

In summary, our study demonstrated for the first time that integrated ERCC1 mRNA and pre EBV-DNA levels may serve as a better predictor for the efficacy of CCRT treatment and long-term survival in stage II NPC patients. High ERCC1 mRNA and high pre EBV-DNA combined result in significant decrease in PFS and OS. These patients may be treated with more aggressive regimen. However, due to different methods in detecting ERCC1 expression level and various cut-off values of ERCC1 level and pretreatment EBV-DNA reported, more studies will be required to validate our results. In addition, the limitation of this study is the relatively small sample size. Harmonization of quantitative assays and large sample size will need international efforts and ultimately to achieve the goal of individualized treatment for stage II NPC patients.

\section{Abbreviations}

NPC, Nasopharyngeal carcinoma

ERCC1, Excision repair cross-complementation group 1

EBV-DNA, Epstein-Barr virus DNA

CCRT, concurrent chemoradiotherapy

OS, overall survival

PFS, progression-free survival

$\mathrm{CR}$, complete response

PR, partial response 
SD, stable disease

PD, progressive disease

$\mathrm{RR}$, The response rate

\section{Declarations}

\section{Acknowledgements}

Not applicable.

\section{Authors' contributions}

L.H., S.C.and M.W contributed to the study design, literature research, interpretation of findings and writing of the manuscript. Y.S., J.L., Z.L.and Y.M contributed to the follow-up, data collection and analyses. P.Y. provided suggestion of statistics. H.H., X.T,and M.Y contributed to critical review of data analyses and critical edit of the manuscript. All authors reviewed and approved the final manuscript.

\section{Funding}

This study was supported by Guangxi Natural Science Foundation (No. 2011GXNSFA018236) and Liuzhou important Scientific Research \& Technology Development Plan (No. 2014J030404) from Science \&Technology of Guangxi. The sponsor had no role in:study design; collection, analyses, or interpretation of data; manuscript writing; or in the decision to publish the results.

\section{Availability of data and materials}

The datasets used and/or analyzed during the current study are available from the corresponding author on reasonable request.

\section{Ethics approval and consent to participate}

This study was approval by the Ethics Committee of Guangxi Medical University and the Forth Affiliated Hospital of Guangxi Medical University, written informed consent was obtained from each patient.

\section{Consent for publication}

Not applicable. 


\section{Competing interests}

The authors declare that they have no competing interests.

\section{Author details}

${ }^{1}$ Department of Oncology, the Forth Affiliated Hospital of Guangxi Medical University, Liuzhou 545005, Guangxi, China

${ }^{2}$ Department of Oncology, The Liuzhou Railway Affiliated Hospital of Guangxi Medical University, Liuzhou 545007, Guangxi, China

${ }^{3}$ Department of Oncology, Qinzhou Hospital of Traditional Chinese Medicine, Qinzhou 535099, Guangxi, China

${ }^{4}$ Department of Oncology, The Yulin First People's Hospital, Yulin 537000, Guangxi, China

${ }^{5}$ Department of Oncology, The Baishe People's Hospital, Baishe, Guangxi, China

${ }^{6}$ Clinical Pharmacology Center, The Third Xiangya Hospital of Central South University, Changsha 410013, Hunan, China

${ }^{7}$ Department of Head and neck surgery, the Forth Affiliated Hospital of Guangxi Medical University, Liuzhou 545005, Guangxi, China

${ }^{8}$ Department of Radiation Onclogy, University Hospitals Cleveland Medical Center, Case Western Reserve University, Cleveland, $\mathrm{OH} 44106$

\section{References}

1. Lang J, Gao L, Guo Y, Zhao C, Zhang C. Comprehensive treatment of squamous cell cancer of head and neck: Chinese expert consensus 2013. Future Oncol. 2014;10:1635-48. doi:10.2217/fon.14.44.

2. $10.3322 /$ caac. 21442

Siegel RL, Miller KD, Jemal A. Cancer statistics. 2018. CA Cancer J Clin. 2018; 68: 7-30. doi: 10.3322/caac. 21442 .

3. Lester DR. Thompson. Update on Nasopharyngeal Carcinoma. Head Neck Pathology. 2007;1(1):816. doi:10.1007/s12105-007-0012-7.

4. Sun Y, Li WF, Chen NY, Zhang N, Hu GQ, Xie FY, et al. Induction chemotherapy plus concurrent chemoradiotherapy versus concurrent chemoradiotherapy alone in locoregionally advanced nasopharyngeal carcinoma: a phase 3, multicentre, randomised controlled trial. The Lancet Oncology. 2016;17(11):1509-20. doi:10.1016/S1470-2045(16)30410-7. 
5. Ye JX, Liang X, Wei J, Zhou J, Liao Y, Lu YL, Tang XQ, Wang AY, Tang Y. Compliance with National Guidelines on the Treatment of Stage II-IVB Nasopharyngeal Carcinoma in a Regional Cancer Center of Southern China. Asian Pac J Cancer Prev. 2018;19(1):115-20. doi:10.22034/apjcp.2018;19.1.115.

6. Chen QY, Wen YF, Guo L, Liu H, Huang PY, Mo HY, et al. Concurrent chemoradiotherapy vs radiotherapy alone in stage II nasopharyngeal carcinoma: phase III randomized trial. J Natl Cancer Inst. 2011;103(23):1761-70. doi:10.1093/jnci/djr432.

7. Ding XC, Fan PP, Xie P, Fan BJ, Yang J, Jiang LY, Bai XB, Yu JM, Hu M. Ten-Year Outcomes of Intensity-Modulated Radiotherapy (IMRT) Combine with Chemotherapy Versus IMRT Alone for Stage II Nasopharyngeal Carcinoma in The Real-World Study (RWD). Cancer Manag Res. 2019;11:8893903. doi:10.2147/CMAR.S218842.

8. Xiao WW, Han F, Lu TX, et al. Treatment outcomes after radiotherapy alone for patients with earlystage nasopharyngeal carcinoma. Int J Radiat Oncol Biol Phys, 2009; 74(4): 1070-1076. doi:10. 1016/j.jijrobp.2008.09.008.

9. $10.1038 / \mathrm{nrc} 3399$

Curtin NJ. DNA repair dysregulation from cancer driver to therapeutic target. Nat Rev Cancer. 2012;12(12): 801 - 17. doi: 10.1038/nrc3399.

10. Martin LP, Hamilton TC, Schilder RJ. Platinum resistance: the role of DNA repair pathways. Clin Cancer Res. 2008;14(5):1291-5. doi:10.1158/1078-0432.ccr-07-2238.

11. Gossage L, Madhusudan S. Current status of excision repair cross complementing-group 1 (ERCC1) in cancer. Cancer Treat Rev. 2007;33(6):565-77. doi:10.1016/j.ctrv.2007;07.001.

12. Besse B, Olaussen KA, Soria JC. ERCC1 and RRM1: ready for prime time? J Clin Oncol. 2013;31(8):1050-60. doi:10.1200/jco.2012.43.0900.

13. Wan J, Chao L, Lee AC, Chen Q. Higher Expression of ERCC1 May Be Associated with Resistance to Adjuvant Platinum-Based Chemotherapy in Gastric Cancer. Cancer Invest. 2017;35(2):85-91. doi:10.1080/07357907.2016;1267741.

14. Liu J, Zhang L, Mao P, Jiang G, Liu L, Wang J, Yang W, Owusu L, Li W. Functional characterization of a novel transcript of ERCC1 in chemotherapy resistance of ovarian cancer. Oncotarget. 2017;8(49):85759-71. doi:10.18632/oncotarget.20482.

15. Tang N, Lyu D, Zhang Y, Liu H. Association between the ERCC1 polymorphism and platinum-based chemotherapy effectiveness in ovarian cancer: a meta-analysis. BMC Womens Health. 2017;17(1):43. doi:10.1186/s12905-017-0393-z.

16. Toffalorio F, Santarpia M, Radice D, Jaramillo CA, Spitaleri G, Manzotti M, Catania C, Jordheim LP, Pelosi G, Peters GJ, Tibaldi C, Funel N, Spaggiari L, et al. 5'-nucleotidase $\mathrm{cN}-\mathrm{Il}$ emerges as a new predictive biomarker of response to gemcitabine/platinum combination chemotherapy in non-small cell lung cancer. Oncotarget. 2018;9(23):16437-50. doi:10.18632/oncotarget.24505.

17. Wang X, Zhu X, Zhang H, Fan X, Xue X, Chen Y, Ding C, Zhao J, Wu G. ERCC1_202 Is A Prognostic Biomarker in Advanced Stage Non-Small Cell Lung Cancer Patients Treated with Platinum-Based Chemotherapy. J Cancer. 2017;8(14):2846-2453. doi:10.7150/jca.19897. 
18. Huang PY, Li Y, Mai HQ, Luo RZ, Cai YC, Zhang L. Expression of ERCC1 predicts clinical outcome in locoregionally advanced nasopharyngeal carcinoma treated with cisplatin-based induction chemotherapy. Oral Oncol. 2012;48(10):964-8. doi:10.1016/j.oraloncology.2012.04.003.

19. Jagdis A, Phan T, Klimowicz AC, Laskin JJ, Lau HY, Petrillo SK, Siever JE, Thomson TA, Magliocco AM, Hao D. Assessment of ERCC1 and XPF protein expression using quantitative immunohistochemistry in nasopharyngeal carcinoma patients undergoing curative intent treatment. Int J Radiat Oncol Biol Phys. 2013;85(5):1340-5. doi:10.1016/j.ijrobp.2012.09.032.

20. Wang D, Zhou J, Zheng J, Zhang J, Chen Y, Li W, Wang R. Predictive value of excision repair crosscomplementation group 1 expression in locoregionally advanced nasopharyngeal carcinoma receiving cisplatin-based concurrent chemoradiotherapy. Cancer Biomark. 2018;21:875-81. doi:10.3233/cbm-170817.

21. Zhou J, Wang D, Zheng JH, Wang Z, Xie B, Zhang WM. Predictive value of excision repair crosscomplementation group 1 protein in locoregionally advanced nasopharyngeal carcinomas receiving cisplatin-based concurrent chemoradiotherapy. J Cancer Res Ther. 2018;14:145-51. doi:10.4103/0973-1482.165866.

22. Guo R, Tang LL, Mao YP, Ma J, et al. Proposed Modifications and Incorporation of Plasma EpsteinBarr Virus DNA Improve the TNM Staging System for Epstein-Barr Virus-Related Nasopharyngeal Carcinoma. Cancer. 2019;125(1):79-89. doi:10.1002/cncr.31741.

23. Sun $\mathrm{P}$, Chen $\mathrm{C}$, Cheng $\mathrm{Y}-\mathrm{K}$, et al. Serologic biomarkers of Epstein-Barr virus correlate with TNM classification according to the seventh edition of the UICC/AJCC staging system for nasopharyngeal carcinoma. Eur Arch Otorhinolaryngol. 2014;271(9):2545-2554. doi:10.1007/s00405-013-2805-5.

24. Zhang W, Chen Y, Chen L, et al. The Clinical Utility of Plasma Epstein-Barr Virus DNA Assays in Nasopharyngeal Carcinoma: The Dawn of a New Era?: a systermatic review and meta-analysis of 7836 cases. Medicine. 2015;94(20):e845. doi:10.1097/MD.0000000000000845.

25. Qu H, Huang Y, Zhao S, Lv W, et al. Prognostic value of Epstein-Barr virus DNA level for nasopharyngeal carcinoma: a meta-analysis of 8128 cases. Eur Arch Otorhinolaryngol. 2020;277(1):9-18. doi:10.1007/s00405-019-05699-9.

26. Hua L, Chen S-J, Chen HH, Huang H-X, Meng Y-L, Lin Z. The significance of quantitative monitoring of plasma EB virus DNA in the diagnosis, treatment and follow-up of stage âष区 NPC. Cancer progress. 2020;18(02):152-6.

27. Friboulet L. Olaussen KA,Pignon JP,et al.ERCC1 isoform expression and DNA repair in nonsmall-cell lung cancer. N Engl J Med. 2013;368(12):1101-10.

28. Friboulet L, Postel-Vinay S, Sourisseau T,et al. .ERCC1 function in nuclear excision and interstrand crosslink repair pathways is mediated exclusively by the ERCC1-202 isoform. Cell Cycle. 2013;12(20):3298-306. doi:10.4161/cc.26309.

29. 10.3892/etm.2015.2284

Song P, Yin, Qin, Lu M, Fu, Bo, Wang B, Zhao Q. (2015). Prognostic value of excision repair crosscomplementation group 1 expression in gastric cancer: A meta-analysis. Experimental and 
Therapeutic Medicine, 2015; 9(4):1393-1400. doi: 10.3892/etm.2015.2284.

30. Olaussen KA, Planchard D, Adam J, Soria JC. [DNA repair pathways and non-small cell lung cancer: clinical perspectives]. Bull Cancer. 2011;98(3):305-22. doi:10.1684/bdc.2011.1327.

31. Han $B, X u X Y$, Zhang CZ, et al. Systematic review on Epstein-Barr virus (EBV) DNA in diagnosis of nasopharyngeal carcinoma in Asian populations. Asian Pac J Cancer Prev. 2012;13(6):2577-2581. doi:10.7314/apjcp.2012.13.6.2577.

32. Chan K, Hung E, Woo J, et al. Early detection of nasopharyngeal carcinoma by plasma Epstein-Barr virus DNA analysis in a surveillance program. Cancer. 2013;119(10):1838-1844. doi:10.1002/cncr.28001.

33. Wong EC, Y, Hung JLC, Ng WT. Potential pitfalls in incorporating plasma Epstein-Barr virus DNA in the management of nasopharyngeal carcinoma. Head Neck. 2020;42(3):446-55. doi:10.1002/hed.26018.

34. Du YY, Luo DH, Sun XS, Tang LQ, Mai HQ, et al. Combining pretreatment plasma Epstein-Barr virus DNA level and cervical node necrosis improves prognostic stratification in patients with nasopharyngeal carcinoma: A cohort study. Cancer Med. 2019;8(16):6841-52. doi:10.1002/cam4.2481.

35. Twu CW, Wang WY, Tsou HH, Lin JC, et al. Effects of Epstein-Barr virus viral load and different treatment modality for stage III nasopharyngeal carcinoma. Head Neck. 2020;1-10. doi:10.1002/hed.26096. doi: 10.1002/hed.26096.

36. Chai SJ, Pua KC, Saleh A, et al. Clinical significance of plasma Epstein-Barr Virus DNA loads in a large cohort of Malaysian patients with nasopharyngeal carcinoma. J Clin Virol. 2012;55(1):34-9. doi:10.1016/j.jcv.2012.05.017.

37. Lin JC, Wang WY, Liang WM, et al. Long-term prognostic effects of plasma Epstein-Barr virus DNA by minor groove binder-probe real-time quantitative PCR on nasopharyngeal carcinoma patients receiving concurrent chemoradiotherapy. Int J Radiat Oncol Biol Phys. 2007;68(5):1342-8. doi:10.1016/j.jjrobp.2007.02.012.

38. Sing-fai Leung ATC, Chan B, Zee, et al. Pretherapy quantitative measurement of circulating EpsteinBarr virus DNA is predictive of posttherapy distant failure in patients with early-stage nasopharyngeal carcinoma of undifferentiated type. Cancer. 2003;98(2):288-91. doi:10.1002/cncr.11496.

39. Deng $\mathrm{Q}$, Yang H, Lin $\mathrm{Y}$, et al. Prognostic value of ERCC1 mRNA expression in non-small cell lung cancer, breast cancer, and gastric cancer in patients from Southern China. int $\mathrm{j}$ clin exp pathol. 2014;7(12):8312-21.

\section{Figures}




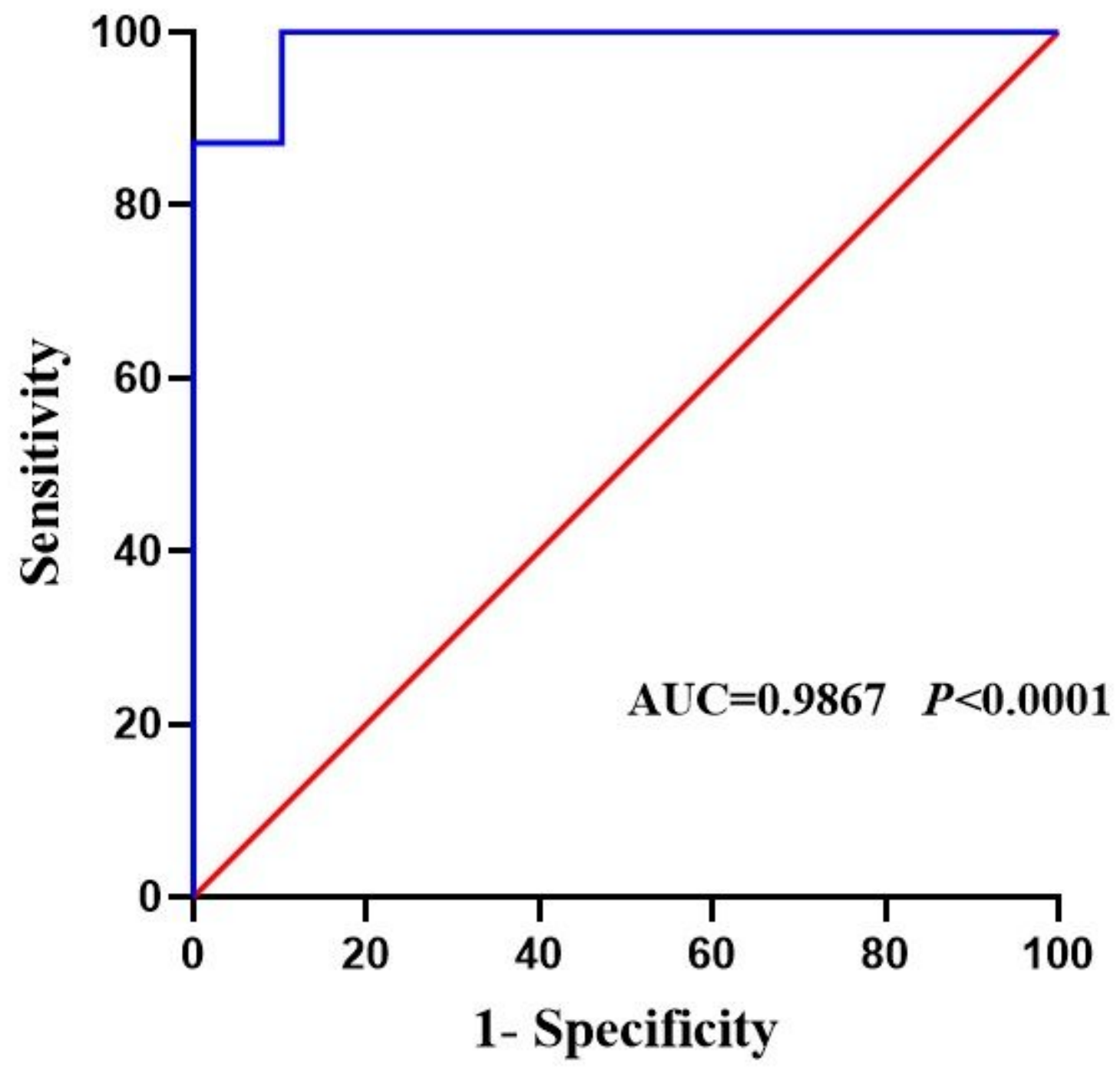

Figure 1

ROC curve for the cut-off points for ERCC1 mRNA that could be obtained by testing ERCC1 mRNA level to predict therapeutic response of stage II NPC patients. 
Number of risk

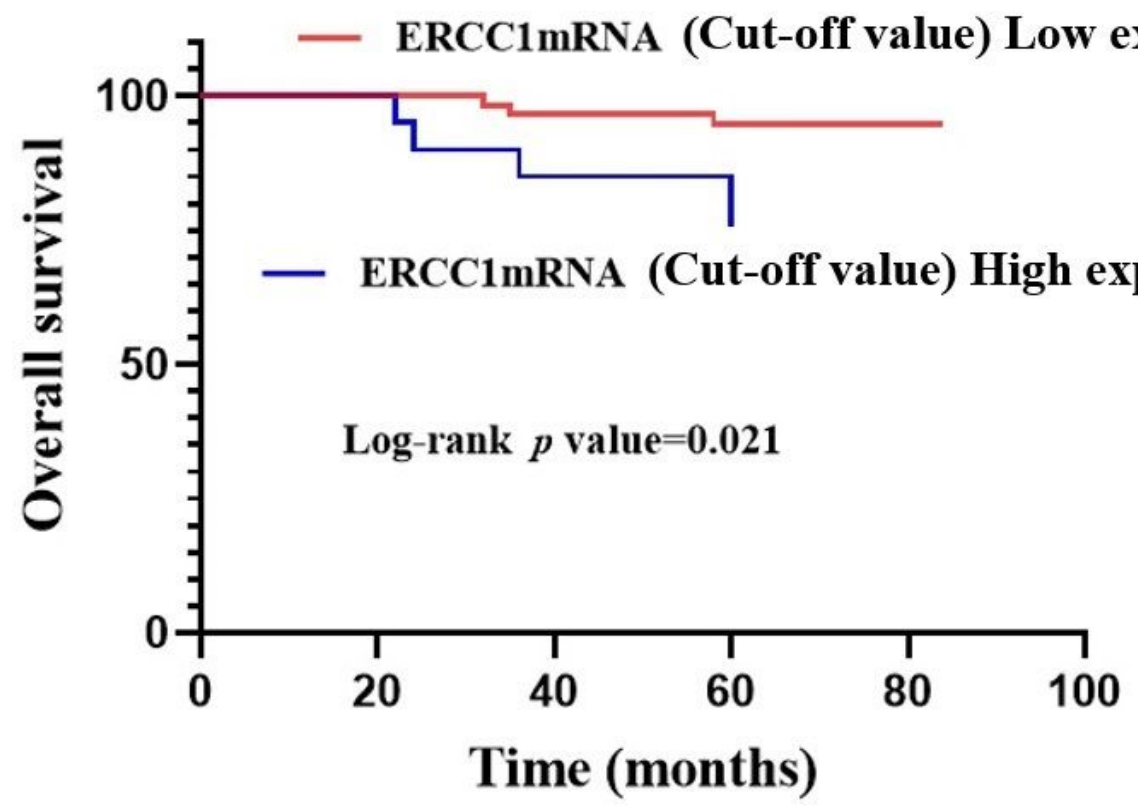

$\begin{array}{llllll}\text { ERCC1mRNA Low expression } & 58 & 58 & 56 & 41 & 3 \\ \text { ERCC1mRNA High expression } & 20 & 19 & 16 & 6 & 0\end{array}$

Figure 2

Kaplan-Meier analysis of ERCC1 mRNA expression based on the cut-off value for OS (A) and PFS(B) in patients with stage II NPC patients.

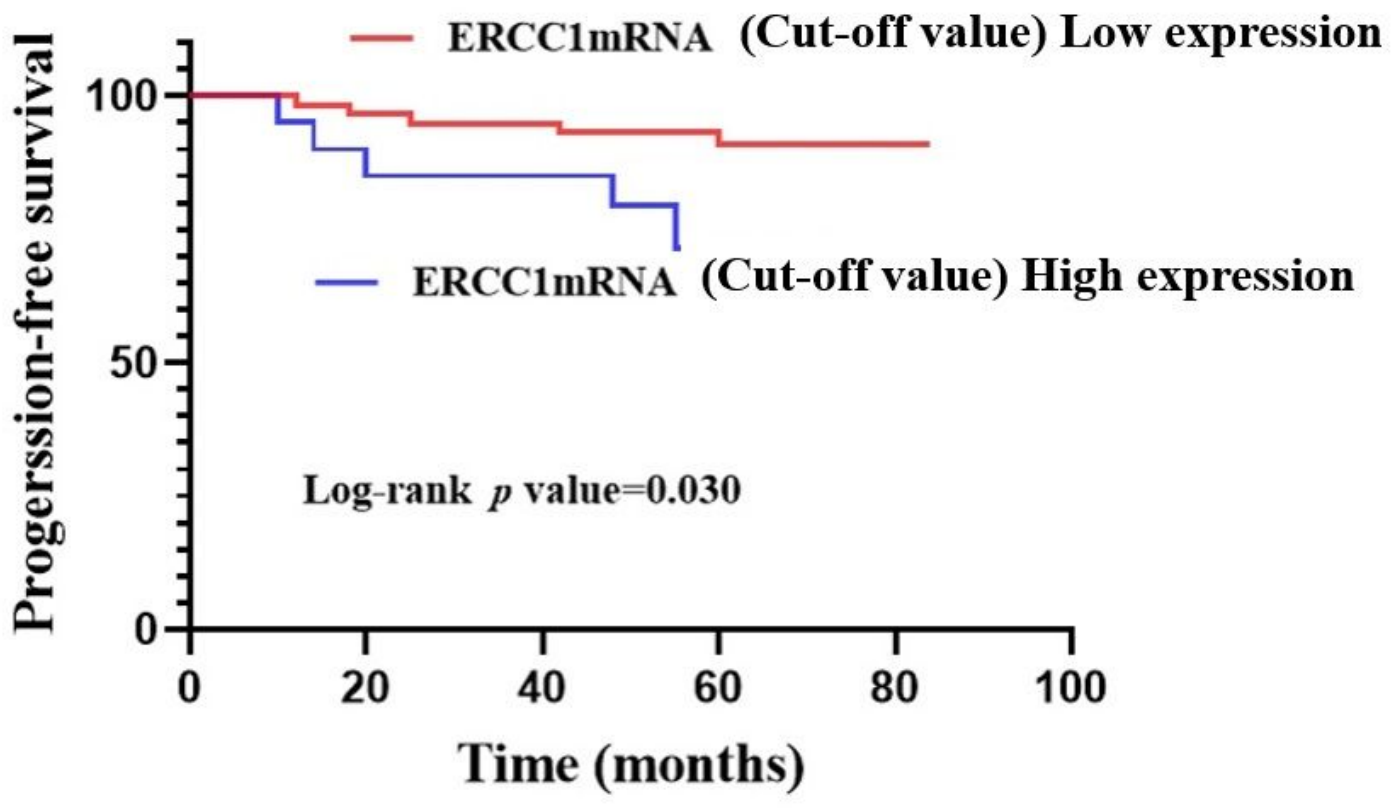

Number of risk

$\begin{array}{lllllll}\text { ERCC1mRNA Low expression } & 58 & 56 & 55 & 39 & 3\end{array}$

$\begin{array}{lllllll}\text { ERCC1mRNA High expression } & 20 & 17 & 16 & 6 & 0\end{array}$ 
Figure 3

Kaplan-Meier analysis of ERCC1 mRNA expression based on the cut-off value for OS (B) in patients with stage II NPC patients.

\section{Number of risk}

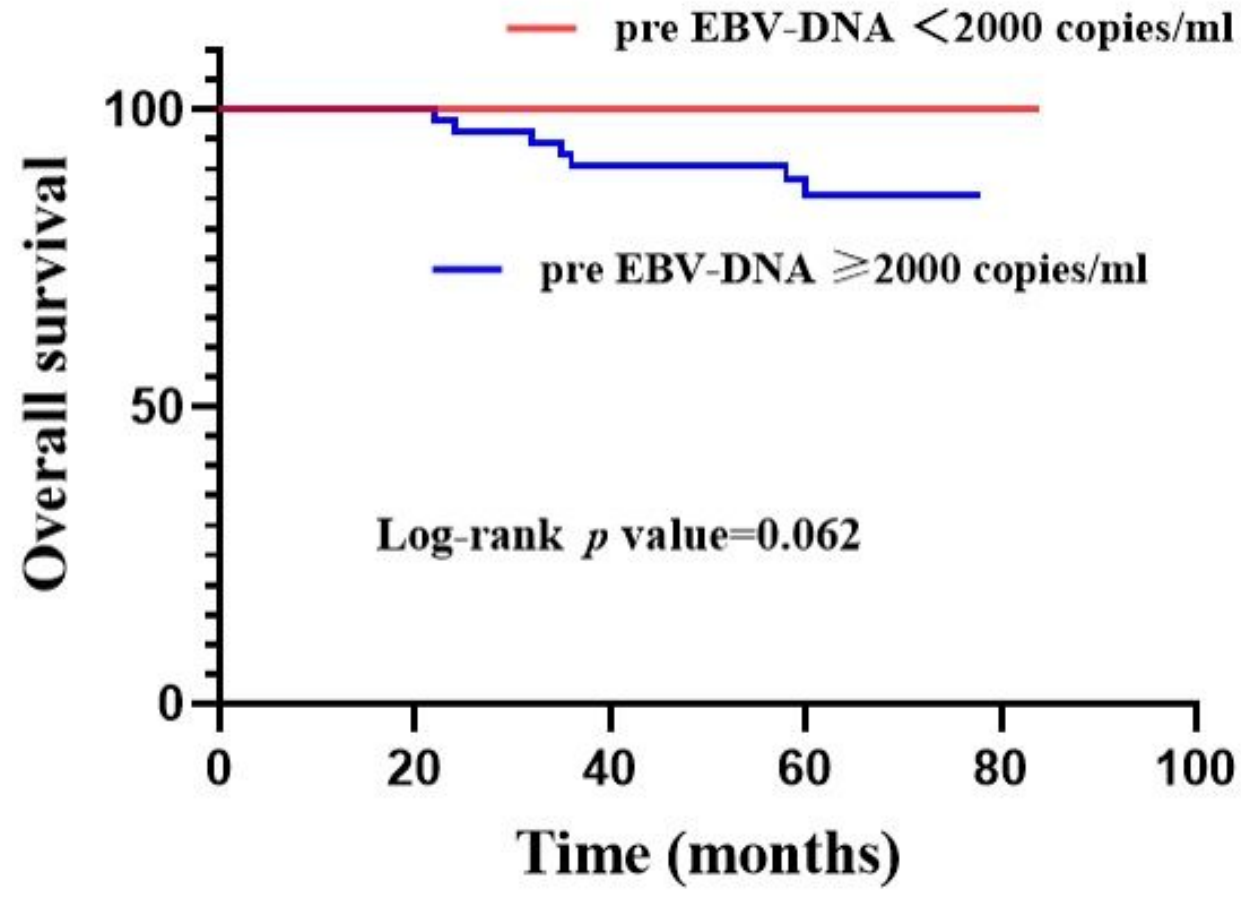

$\begin{array}{llllll}\text { ERCC1mRNA Low expression } & 24 & 24 & 24 & 20 & 3 \\ \text { ERCC1mRNA High expression } & 54 & 54 & 48 & 27 & 0\end{array}$

Figure 4

Kaplan-Meier curves of OS (A) and PFS (B) according to pretreatment plasma EBV-DNA levels ( $₫ 2000$ copies/ ml vs $\geq 2000$ copies/ ml) for stage II NPC patients. 


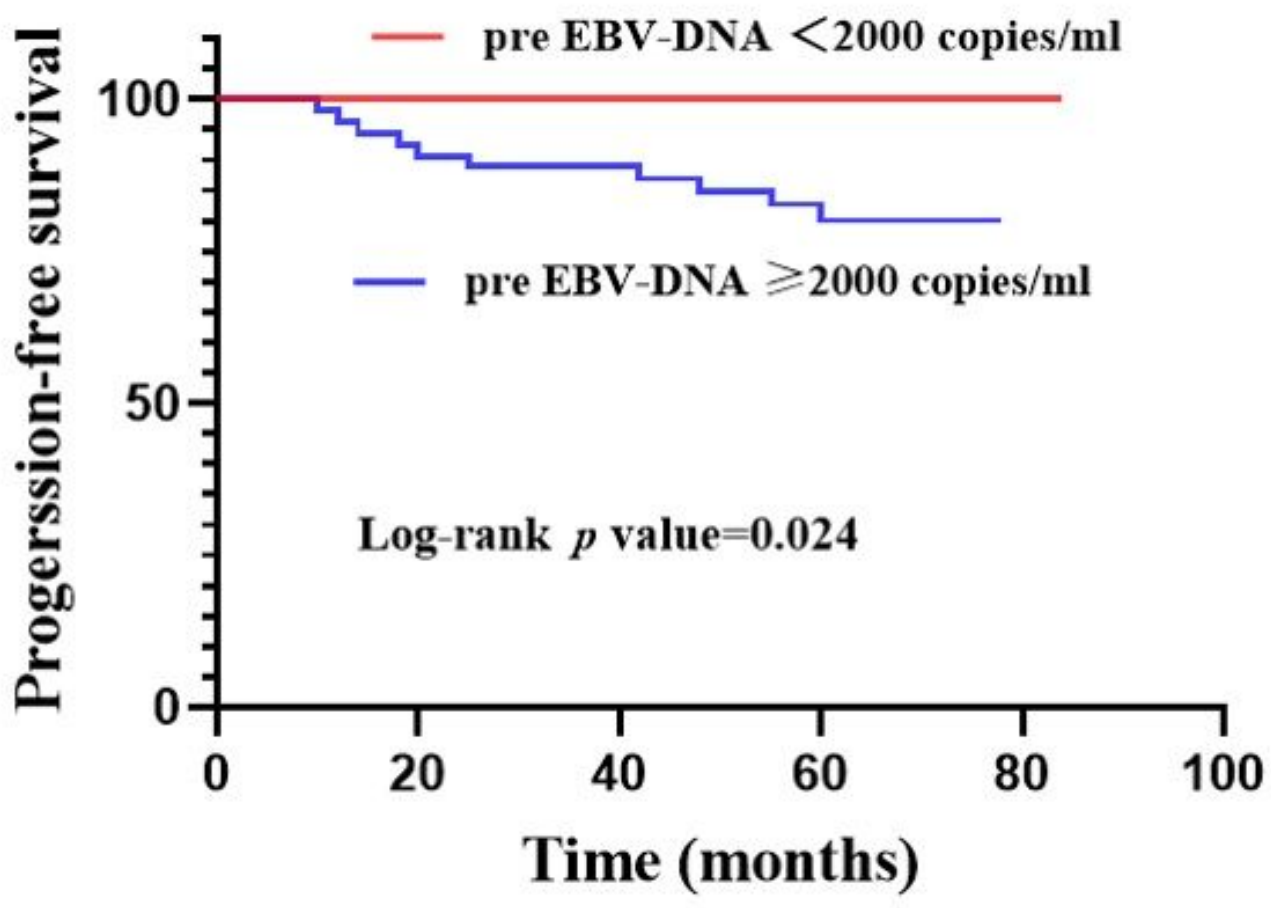

Number of risk

$\begin{array}{lllllll}\text { ERCC1mRNA Low expression } & 24 & 24 & 24 & 20 & 3\end{array}$

$\begin{array}{lllllll}\text { ERCC1mRNA High expression } & 54 & 49 & 47 & 25 & 0\end{array}$

Figure 5

Kaplan-Meier curves of OS (A) and PFS (B) according to pretreatment plasma EBV-DNA levels ( $₫ 2000$ copies/ ml vs $\geq 2000$ copies/ ml) for stage II NPC patients. 


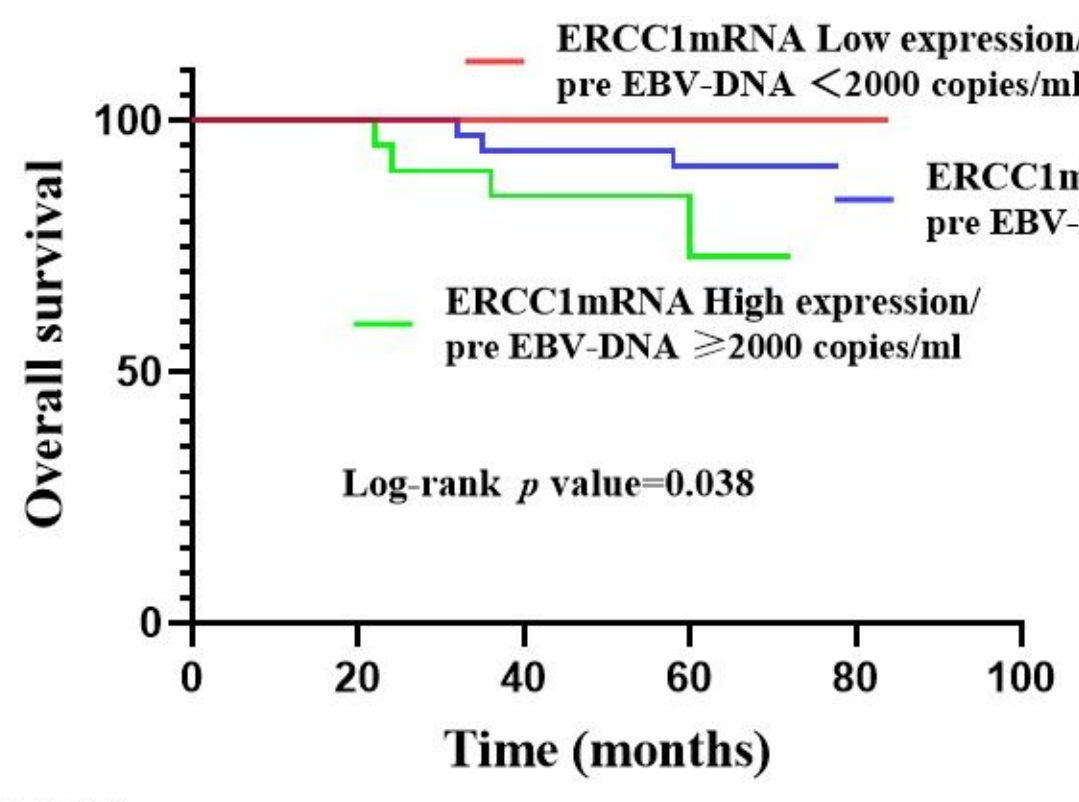

Nomber of risk

ERCC1mRNA Low expression/ pre EBV-DNA $<2000$ copies/ml ERCC1mRNA Low expression/ pre EBV-DNA $\geqslant 2000$ copies $/ \mathrm{ml}$ ERCC1mRNA High expression/ pre EBV-DNA $\geqslant 2000$ copies $/ \mathrm{ml}$

24

34

20

\section{4}

34

20

\begin{abstract}
24
\end{abstract}
32

16
20

21

6
3

0

0

Figure 6

Kaplan-Meier survival curves of stage II NPC patients displaying different combinations of ERCC1 expressions based on the cut-off and pre EBV-DNA level. OS (A), PFS (B). 


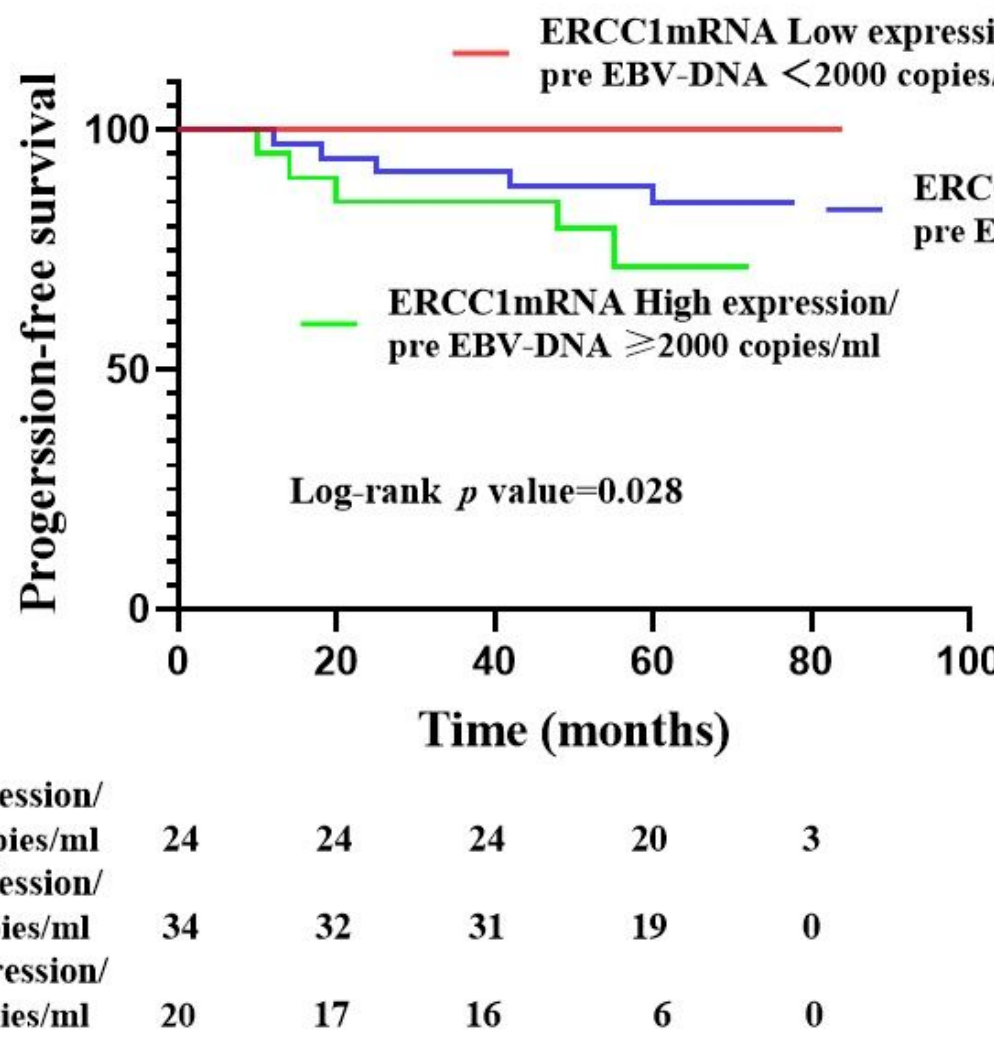

Figure 7

Kaplan-Meier survival curves of stage II NPC patients displaying different combinations of ERCC1 expressions based on the cut-off and pre EBV-DNA level. OS (A), PFS (B). 


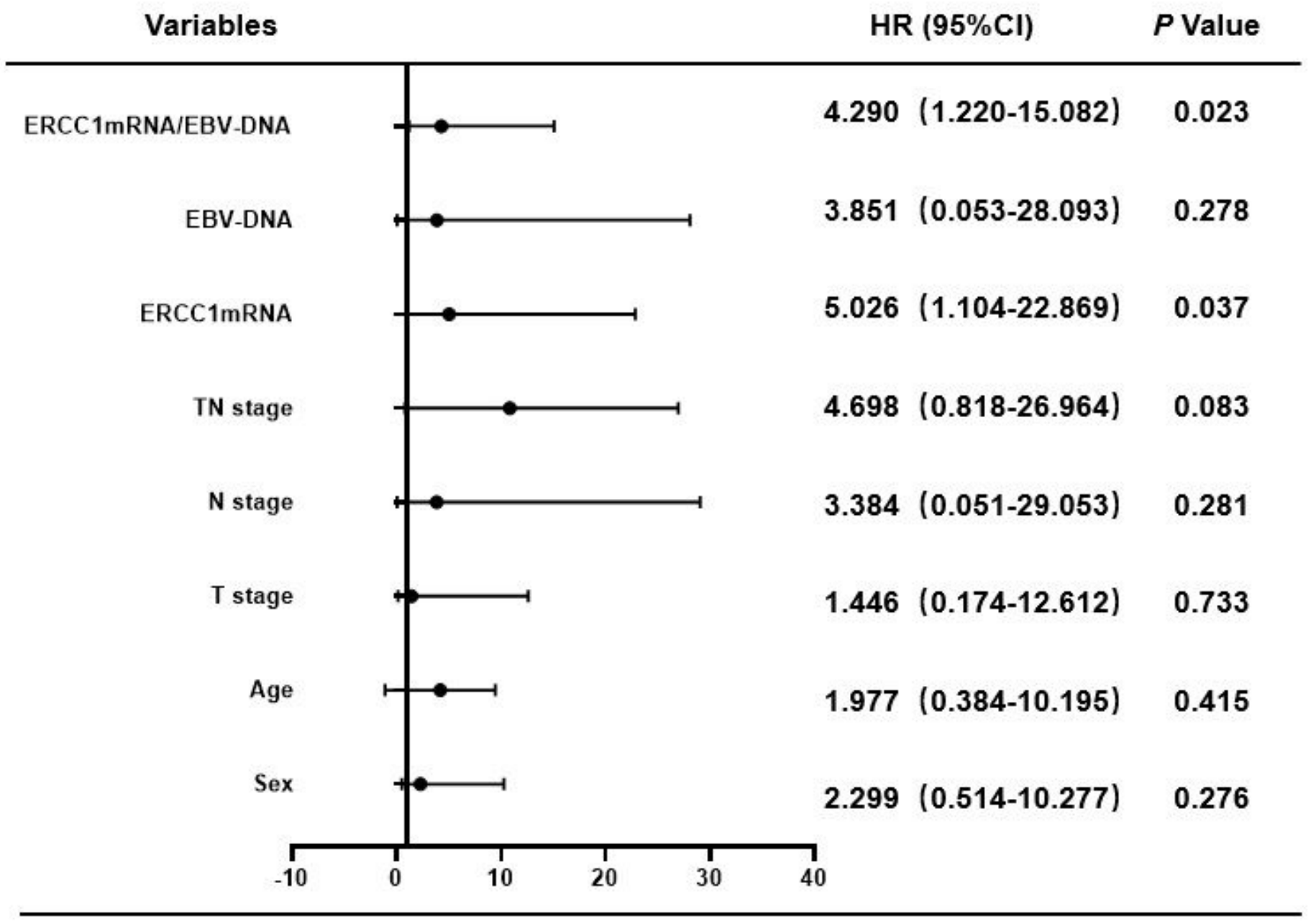

Figure 8

Forest plot of the association between clinicopathological variables and OS (A) and PFS (B) by subgroup for stage II NPC patients. 


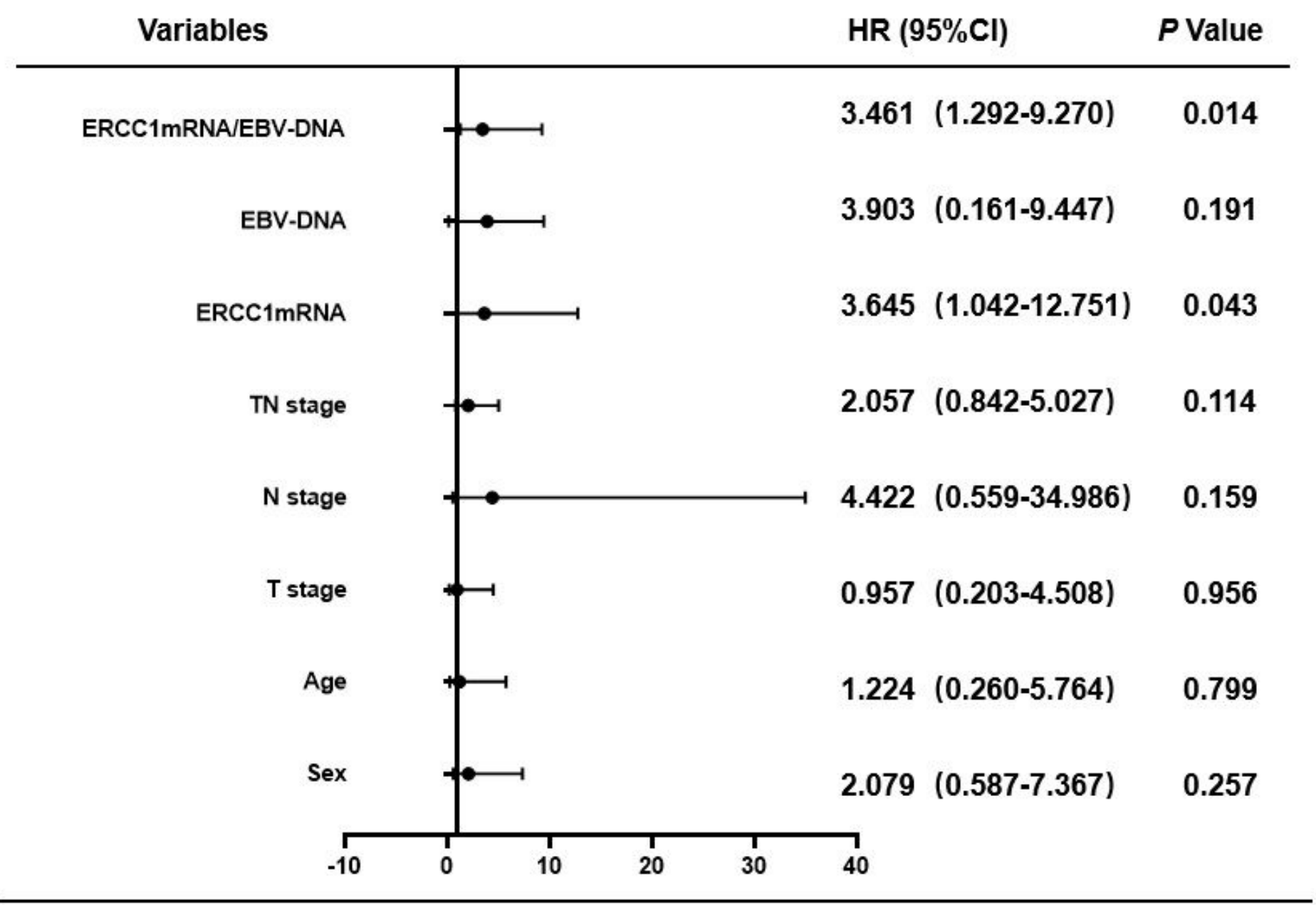

Figure 9

Forest plot of the association between clinicopathological variables and OS (A) and PFS (B) by subgroup for stage II NPC patients. 